\title{
Preliminary Phytochemical Analysis and Evaluation of Anthelmintic Activity of Pistacia vera Endocarp
}

\section{K. Anandarajagopal ${ }^{1 *}$, Abdullah Khan ${ }^{1}$, Sheerlin Ting Enn Xuan ${ }^{1}$, Ee Kok Mun ${ }^{1}$, Kai Bin Liew², Mei Jun Loy ${ }^{3}$, Bama Menon ${ }^{1}$, Tan Ching Siang ${ }^{1}$}

${ }^{1}$ Centre of Excellence for Pharmaceutical Sciences, School of Pharmacy, KPJ Healthcare University College, Nilai, Negeri Sembilan, Malaysia.

${ }^{2}$ Faculty of Pharmacy, University of Cyberjaya, Cyberjaya, Selangor, Malaysia.

${ }^{3}$ Faculty of Engineering, Universiti Teknologi Malaysia, Skudai, Malaysia.

*Corresponding author's E-mail: anandkarg@gmail.com

Received: 22-06-2020; Revised: 17-09-2020; Accepted: 25-09-2020; Published on: 20-10-2020.

\section{ABSTRACT}

Medicinal plants have a distinct role in treating and preventing various human ailments. Most of the countries rely on their traditional practices using medicinal plants to meet some of their primary healthcare needs. Helminth parasites are most common to infect human beings particularly the infants and cause severe morbidity worldwide. Anthelmintics derived from plant sources may be very beneficial to mankind in the treatment of these parasitic infections. The present study was aimed to evaluate the anthelmintic activity of Pistacia vera endocarp against the earthworms, Pheretima posthuma. Water and ethanol extracts of $P$. vera were obtained by cold maceration method. Preliminary phytochemical tests were performed for both the extracts prior to the evaluation of their anthelmintic effect. Alkaloids, flavonoids, carbohydrates, and glycosides were present in both the extracts. But tannins were present only in ethanol extract. A dose-dependent anthelmintic activity was observed. Ethanol extract showed more potent anthelmintic activity than water extract that is evident from the difference in the time taken by each extract to paralyze or kill the worms. The results suggest that the presence of tannins in ethanol extract would be the main responsible factor for the anthelmintic activity and the other complex mixture may produce synergistic action.

Keywords: Pistacia vera, endocarp, Pheretima posthuma. ethanol extract, tannins.

QUICK RESPONSE CODE $\rightarrow$

DOI:

10.47583/ijpsrr.2020.v64i02.016

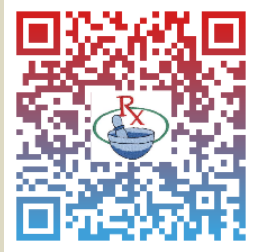

DOI link: $\underline{\text { http://dx.doi.org/10.47583/ijpsrr.2020.v64i02.016 }}$

\section{INTRODUCTION}

$\mathrm{H}$ elminth infection is one of the most prevalent diseases among humans and animals. During the past few decades, the control of helminthiasis is still not effective despite abundant advances in understanding the transmission mode and treatment of these parasitic infections ${ }^{1}$. This parasitic disease contributes to the increased incidences of malnutrition, pneumonia, eosinophilia, and anemia to the public in developing countries. Although most of the worm infections are generally limited to tropical areas, but those who visit these regions are also susceptible to such infections and some of these infection may be prevalent in temperate climates as well².

Helminthiasis is a disease in which worms such as tapeworm, pinworm or roundworm infested into a part of the human body. Typically, these parasites live in the gastrointestinal tract (GIT) but may also move into other organs such as the liver. The soils get contaminated when infected people excrete feces with helminth eggs especially in areas with inadequate sanitation. Contaminated food with helminth eggs or larvae can then infect other people through ingestion or transdermal permeation by infective larvae present in the soil (hookworms). The most common parasitic diseases are schistosomiasis, filariasis, and onchocerciasis (river blindness) besides other severe morbidities ${ }^{3}$.

Anthelmintic are medicines act locally or systemically to remove worms from the GIT or to exterminate matured helminths that enter other tissues and organs. Most of the existing anthelmintics in the market may cause undesirable side effects including abdominal discomfort, diarrhoea, headache, loss of appetite, nausea, and vomiting. Anthelmintics derived from the natural sources may be beneficial to mankind in the treatment of these parasitic worm infections ${ }^{4}$.

Plants have been used by people as a source of drug around the world since thousands of years. Medicinal plants are rich in phytochemical ingredients that can be used to develop novel herbal drugs ${ }^{5}$. Medicinal plants are used to augment and maintain mental, spiritual and physical health ${ }^{6}$. Herbal medicines are used for the treatment various diseases and disorders due to their complex phytochemical nature and thus producing synergistic actions. The interaction of plant constituents with each other can either eliminate harmful effects and 
produce beneficial or both. Plant-derived compounds also have the ability to mitigate hard-to-treat diseases or to prevent the development of certain conditions and illnesses ${ }^{7}$.

Traditional medicines retained their representation for cultural and historical reasons despite the availability of modern medicines ${ }^{1}$. Although most of the diseases are often being treated by laboratory synthetic medicines, some of these medications tend to damage the body owing to their undesirable side effects. Traditional medicines have comparatively lesser complications than modern medicines and considered safe. Therefore, the acceptance and demand of medicinal plants and their products by the public is progressively increased and strengthened ${ }^{7}$.

Pistacia vera belongs to the family, Anacardiaceae and commonly known as pistachio nut. It is known as Kai Xin Guo in Chinese and Kacang Pistachio in Bahasa Malaysia. The pistachio nuts are well known for their nutritional value and are consumed globally for their beneficial health effects and therefore the pistachio nuts have significant economic importance as well. Pistachios have high contents of unsaturated fatty acids and low in saturated fatty acids, and it is a rich source of nutrients owing to the presence of proteins antioxidants, vitamins, dietary fibers, and minerals in the nuts.

The seed and kernel of $P$. vera have potential antifungal, antiviral and antibacterial activities ${ }^{8}$. Pistachio nuts are ranked among most nutritious food products with highest phenolic contents and antioxidant potential. Consumption of pistachio can be beneficial in cardiovascular disease (CVD) due to its actions such as controlling the lipid levels inflammation, endothelial function, oxidative status and blood pressure ${ }^{9}$.

Raw shell and roasted salted pistachios are rich in polyphenol fractions. The extracts from raw pistachio showed more bactericidal effect against gram-positive bacteria such as $S$. aureus and $L$. monocytogenes than the extracts of roasted salted pistachios. Pistachio extracts can be used as food preservative due to their bacteriostatic and bactericidal activity and may find application in the topical treatment of $S$. aureus infections ${ }^{10}$. So far, no research has been reported to assess the anthelmintic activity of $P$. vera endocarp. Hence, the present study was undertaken to evaluate the effectiveness of $P$. vera endocarp against earthworms, Pheretima posthuma.

\section{MATERIALS AND METHODS}

\section{Plant parts used}

The Pistacia vera nuts were collected and authenticated by Dr, Mohd Firdaus Ismail, Biodiversity unit, Institute of Bioscience, Universiti Putra Malaysia. The specimen voucher number is MFI 0147/19.

\section{Extraction of plant material}

The endocarp of $P$. vera nuts was separated and washed with distilled water and then allowed to shade dried for 7 days at room temperature. The dried materials were powdered using mechanical blender and the coarse powder was collected and stored in an airtight container for later use. The coarsely powdered $P$. vera endocarp (500 gm) was equally divided into two portions and extracted with $500 \mathrm{ml}$ of $95 \%$ ethanol and distilled water respectively using cold maceration method for 6 days. The extraction was carried out at the room temperature. The extracts were filtered and concentrated by rotary vacuum evaporator. The extraction efficiency was determined based on dry weight of the concentrated extracts. The endocarp extracts were stored at 4 으 in refrigerator until further use $\mathrm{e}^{11}$

\section{Qualitative Phytochemical Screening}

Both water and ethanol extracts of $P$. vera endocarp were subjected to preliminary phytochemical screening using relevant chemical tests as per the standard procedure to identify the presence of secondary metabolites such as tannins, terpenoids, flavonoids, alkaloids, saponins, proteins, carbohydrates and glycosides ${ }^{12}$. The results are tabulated in table 1.

\section{Evaluation of Anthelmintic Activity}

\section{Worms Collection}

Adult earthworms (Pheretima posthuma) were collected from moist soil in Kota Seriemas, Nilai, Negeri Sembilan. The earthworms were washed to remove all dirt and soil particles with normal saline. The earthworms with $3-5 \mathrm{~cm}$ in length and $0.1-02 \mathrm{~cm}$ in width were used for the anthelmintic study due to its anatomical and physiological resemble with the intestinal roundworm parasites of human beings ${ }^{13}$.

\section{Screening of Anthelmintic Activity}

The water and ethanol extracts of $P$. vera endocarp were tested for their anthelmintic activity against adult earthworms $\left(P\right.$. posthuma) by in-vitro method ${ }^{14}$. Two different concentrations (50 and $100 \mathrm{mg} / \mathrm{ml}$ ) of both extracts of $P$. vera endocarp and the standard drug albendazole were prepared in distilled water. The worms were divided into 7 groups $(n=6)$. Worms in group I were served as control and placed into a plate containing only distilled water. Group II and III were treated with albendazole $50 \mathrm{mg} / \mathrm{ml}$ and $100 \mathrm{mg} / \mathrm{ml}$ respectively, Group IV-VII used for tested samples of water and ethanol extracts of $P$. vera endocarp at a dose of $50 \mathrm{mg} / \mathrm{ml}$ and 100 $\mathrm{mg} / \mathrm{ml}$ respectively. The earthworms were placed into a petri dishes containing distilled water, different concentrations of endocarp extracts and standard, albendazole and the time taken for paralysis and death of individual worms were observed. When there is no movement of any sort after transferred to normal saline, was recorded as time of paralysis. Death was confirmed when the worms lost their motility completely and failed to respond even after a touch with a needle followed by fading of their color. Mean values of paralysis time and 
death time of $P$. posthuma earthworms are presented in table 2

\section{Statistical Analysis}

The statistical analysis was carried out by one-way ANOVA using SPSS software. All the data is represented as mean \pm SEM.

\section{RESULTS}

\section{Characteristics and Percentage Yield of Extracts}

The consistency, color and percentage yield of both water and ethanol extracts for $P$. vera endocarp were observed. Both extracts are semisolid in nature and dark brown. Water extract showed highest percentage yield (1.8\%) than ethanol extract $(0.75 \%)$.

\section{Qualitative Phytochemical Screening}

Table 1 shows the list of phytoconstituents present in water and ethanol extracts of $P$. vera endocarp. The qualitative phytochemical screening revealed the presence of flavonoids, alkaloids, carbohydrates and glycosides while absence of saponins, terpenoids, proteins were observed in both extracts. Whereas, tannins were found in ethanol extract.
Table 1: Phytochemicals present in the extracts of $P$. vera endocarp

\begin{tabular}{|c|c|c|}
\hline Phytoconstituents & $\begin{array}{c}\text { Water } \\
\text { extract }\end{array}$ & $\begin{array}{c}\text { Ethanol } \\
\text { extract }\end{array}$ \\
\hline Alkaloids & + & + \\
\hline Tannins & - & + \\
\hline Terpenoids & - & - \\
\hline Flavonoids & + & + \\
\hline Saponins & - & - \\
\hline Proteins & - & - \\
\hline Carbohydrates and & + & + \\
glycosides & & \\
\hline$+=$ present; - = absent & & \\
\hline
\end{tabular}

\section{Anthelmintic Activity}

Table 2 shows the anthelmintic effect of water and ethanol extracts for $P$. vera endocarp against the earthworms, $P$. posthuma. All the results were compared with standard drug, albendazole. The ethanol extract of $P$. vera endocarp was found to possess highly significant $(p<0.001)$ dose dependent anthelmintic activity than water extract of $P$. vera endocarp. There was no significant anthelmintic activity observed against the worms treated with water extract.

Table 2: Anthelmintic activity of extracts for $P$. vera endocarp

\begin{tabular}{|l|c|c|c|}
\hline Treatment & $\begin{array}{c}\text { Concentration } \\
(\mathbf{m g} / \mathbf{m l})\end{array}$ & $\begin{array}{c}\text { Time Taken for Paralysis } \\
(\mathbf{m i n})(\mathbf{M e a n} \pm \mathbf{S E M})\end{array}$ & $\begin{array}{c}\text { Time Taken for Death } \\
\text { (min) (Mean } \pm \text { SEM) }\end{array}$ \\
\hline Control (Normal Saline) & - & - & - \\
\hline Standard (Albendazole) & 50 & $27.83 \pm 1.94$ & $35.83 \pm 0.87$ \\
\hline Ethanol extract & 100 & $25.17 \pm 1.33$ & $35.67 \pm 1.02$ \\
\hline Water extract & 50 & $11.17 \pm 2.32 * * *$ & $24.67 \pm 2.06^{* * *}$ \\
\hline & 100 & $7.33 \pm 0.92^{* * *}$ & $15.5 \pm 1.93^{* * *}$ \\
\hline
\end{tabular}

Data is represented as mean $\pm S E M ; n=6 ; p<0.05=$ low significant; $p<0.01=$ significant; $p<0.001=$ highly significant;

\section{DISCUSSION}

Both water and ethanol extracts of $P$. vera endocarp exhibited significant anthelmintic effect to cause paralysis and death of worms at a dose of $50 \mathrm{mg} / \mathrm{ml}$ and $100 \mathrm{mg} / \mathrm{ml}$. The anthelmintic activity was well comparable with standard drug of Albendazole $(50 \mathrm{mg} / \mathrm{ml}$ and $100 \mathrm{mg} / \mathrm{ml}$ ). The qualitative phytochemical analysis of both water and ethanol extract of $P$. vera endocarp showed the presence of flavonoids, alkaloids and carbohydrates and glycosides and the absence of saponins, terpenoids and proteins. Tannins are observed only in ethanol extract of $P$. vera endocarp.

According to the observation, ethanol extract shows high anthelmintic activity than water extract. This may be attributed to the presence of tannins in ethanol extract only. Ethanol extract had better penetrating characteristics in cell walls, causing the plant materials to release high concentrations of polyphenol. The low anthelmintic activity of the water extract against $P$. posthuma worm may be due to the enzyme polyphenol oxidase. This enzyme is able to reduce polyphenols levels in the water extract while it is inactive in ethanol solvent ${ }^{15}$.

Chemically tannins belong to polyphenolic compounds which have anthelmintic activity. It is believed that tannins present in the ethanol extracts of $P$. vera endocarp exert its action by uncoupling oxidative phosphorylation that interfere with energy generation in helminth parasites. Tannins also have the ability to bind to the glycoprotein on the cuticle of the worms or free proteins in the gastrointestinal tract of host animal and cause death ${ }^{16}$. 
Alkaloids are found to reduce the glucose support for worms by providing the suppressive effect of sucrose distribution to the small intestines. These effects combine with the antioxidant effects of flavonoids and can reduce the production of nitrates needed in protein synthesis. Moreover, alkaloids are believed to cause paralysis acting on the central nervous system of worms ${ }^{17}$. These findings suggest that the potent anthelmintic activity exerted by ethanol extract of $P$. vera endocarp might be due to the presence of tannins as well as synergistic action of the complex mixture of compounds present in the extract.

\section{CONCLUSION}

The present study reveals the anthelmintic activity of ethanol extract of $P$. vera endocarp extracts against the $P$. posthuma worms which might be due to the presence of tannins and other secondary metabolites such as flavonoids and alkaloids. These results scientifically support the anthelmintic effect of $P$. vera endocarp. However, this invitro study is not enough to exploit the development of novel herbal anthelmintic drug. Therefore, further studies are necessary to isolate the responsible bioactive compounds and to establish the exact mechanism of action to develop the potent novel herbal anthelmintic drug.

Acknowledgement: The authors are grateful to the management of KPJ Healthcare University College, Persiaran Seriemas, Kota Seriemas, Nilai, Negeri Sembilan, Malaysia, for providing support, facilities, funding and technical assistance.

\section{REFERENCES}

1. Gulnaz AR, Savitha G, Evaluation of anthelmintic activity of different leaf and stem extract of Sida cordata Burm. F., International Journal of Current Microbiology and Applied Sciences, 2(11), 2013, 247-255.

2. Agrahari AK, Meher A, Padhan AR, Dash S, Assessment of anthelmintic activity of Jussiaea hyssopifolia G. Don, Asian Journal of Plant Science and Research, 1(4), 2011, 87-91.

3. Gnaneswari $K$, Padma $Y$, Raju RRV, Jayaveera $K N$, In vitro anthelmintic activity of Leonotis nepetiifolia (L.) R. Br., A potential medicinal plant, Journal of Chemical and Pharmaceutical Research, 5(2), 2013, 345-348.

4. Priyanka K, Ramanjaneyulu K, Himabindhu J, Phytochemical screening and in vitro anthelmintic activity of Alysicarpus monilifer, International Journal of Pharmacognosy and Phytochemical Research, 8(10), 2016, 1630-1633.

5. Shakya AK, Medicinal plants: Future source of new drugs. International Journal of Herbal Medicine, 4(4), 2016, 59-64.
6. Akinyemi, Oyewole $\mathrm{S}$, Jimoh $\mathrm{K}$, Medicinal plants and sustainable human health: A review, Horticulture International Journal, 2(4), 2018, 194-195.

7. Jamshidi-kia F, Lorigooini Z, Amini-khoei $\mathrm{H}$, Medicinal plants: Past history and future perspective, Journal of Herbmed Pharmacology, 7(1), 2018, 1-7.

8. Ozcelik B, Aslan M, Orhan I, Karaoglu T, Antibacterial, antifungal, and antiviral activities of the lipophylic extracts of Pistacia vera, Microbiological Research, 2005, 159-164.

9. Gebauer S, West S, Kay C, Alaupovic P, Bagshaw D, KrisEtherton $\mathrm{P}$, Effects of pistachios on cardiovascular disease risk factors and potential mechanisms of action: A doseresponse study, The American Journal of Clinical Nutrition, 88, 2008, 651-659.

10. Bisignano C, Filocamo A, Faulks RM, Mandalari G, In vitro antimicrobial activity of pistachio (Pistacia vera L.) polyphenols, Federation of European Microbiological Societies, 341, 2013, 62-67.

11. Karthy E, Ranjitha P, Mohankumar A, Antimicrobial potential of plant seed extracts against multidrug resistant methicillin resistant Staphylococcus aureus (MDR-MRSA). International Journal of Biology, 1(1), 2009, 34-40.

12. Harborne J. (1973). Phytochemical methods- A guide to modern techniques of plant analysis, Springer Science Business Media, 3(14), 1- 317.

13. Kakade RT, Sandu N, Senthilkumar KL, In vitro anthelmintic activity of leaves and stems extract of Biophytum sensitivum Linn. Asian Journal of Plant Science and Research, 3(6), 2013, 64-68.

14. Ngbolua N, Moke EL, Blaise M, Bongo N, Kapepula PM, Ngombe NK, et al, Selenium content, anthelmintic, antioxidant and antibacterial activities of Artocarpus heterophyllus Lam. from Ubangi Ecoregion in Democratic Republic of the Congo. American Journal of Biomedical Science and Research, 6(2), 2019, 135-141.

15. Husori DI, Sumardi, Tarigan H, Gemasih S, Ningsih SR, In-vitro anthelmintic activity of Acanthus ilicifolius leaves extracts on Ascaridia galli and Pheretima posthuma. Journal of Applied Pharmaceutical Science, 8(2), 2018, 164-167.

16. Jayaraman A, Murali, A, Sathiya R, Saraswathy, GR, Azamthulla $M$, In vitro anthelmintic activity of leaf ethanolic extract of Cassia alata and Typha angustifolia, SASTech Journal, 14(2), 2015, 41-44.

17. Husori Di, Sumardi Ht, Gemasih S, Ningsih Sr. In vitro anthelmintic activity of Acanthus ilicifolius leaves extracts on Pheretima posthuma, Journal of Applied Pharmaceutical Sciences, 8(2), 2018, 164-167.

Source of Support: None declared.

Conflict of Interest: None declared.

For any question relates to this article, please reach us at: editor@globalresearchonline.net New manuscripts for publication can be submitted at: submit@globalresearchonline.net and submit_ijpsrr@rediffmail.com 